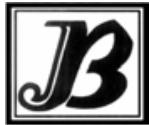

J. bio-sci. 16: 129-131, 2008

ISSN 1023-8654

http://www.banglajol.info/index.php/JBS/index

-Short Communication

\title{
SEED GERMINATION RESPONSE OF RAUVOLFIA SERPENTINA BENTH. TO CERTAIN PHYSICAL AND CHEMICAL TREATMENTS
}

\author{
D Paul, N K Paul* and P K Basu \\ Department of Botany, North Bengal University, Raja Rammohanpur, Darjeeling, India \\ * Department of Botany, University of Rajshahi, Rajshahi-6205, Bangladesh
}

Although Rauvolfia serpentine Benth. can be propagated by both seeds and vegetative propagules, growth of plant and root yield are better in those raised from seeds (Badhwar et al. 1956). But germination of seeds is much lower (Nayar 1956, Dutta et al. 1962). Moreover, collection of seeds from wild sources is both laborious and costly, inasmuch as the plants grow sporadically and the seeds ripen a few at a time. If the ripe seeds are not collected in time, they drop off to the ground and are lost. For these reasons seeds are not easily available from wild sources. Therefore, in the present investigation attempts have been made to improve the germination percentage of seeds of $R$. serpentina.

Freshly collected seeds of $R$. serpentina were subjected to the following treatments: 1 . Mechanical scarification: Individual seeds were rubbed against sand paper or grind stone or nicked with a needle. 2. Hot water soaking: The seeds held in a netting wire were soaked in hot water at $80 \pm 2^{\circ} \mathrm{C}$ for $5,10,15$ and 20 minutes. 3. Sulphuric acid treatment: The seeds were dipped in conc. sulphuric acid for $3,5,10,15,30,40$, 60 and 90 minutes, after which the seeds were thoroughly washed in running tap water and dried on paper towels. 4. Hydrochloric acid treatment: As in sulphuric acid treatment. 5. Heat treatment: For dry heating, the seeds were exposed to temperatures of 70,80 and $90^{\circ} \mathrm{C}$ for $16,24,48,72$ and 96 hours duration in an oven. 6. Pre-sowing seed treatment with chemicals: Seeds were soaked for 24 hours in the following chemicals: $1 \%$ boric acid, $1 \%$ calcium hydroxide, $1 \%$ sodium dihydrogen phosphate, $1 \%$ potassium nitrate, $0.5 \%$ thiourea, $100 \mathrm{ppm} \mathrm{GA}$ and $100 \mathrm{ppm}$ NAA. Interactive effects of $\mathrm{KNO}_{3}$ with $\mathrm{GA}_{3}$ and NAA were also investigated. Pre-soaked seeds were re-dried for 24 hours in a stream of air. Untreated seeds were used as control. Germination tests were replicated thrice. Seeds were placed on two layers of blotting paper in petri dishes of $9 \mathrm{~cm}$ diameter. A seed regarded as germinated when radicle was approximately $5 \mathrm{~mm}$ in length.

Seed scarification with sand paper increased germination percentage to some extent, but grinding of seeds with stone or nicking with a needle were not effective (Table 1). Sinha et al. (1993) reported that scarification of seeds of Trigonella corniculata with sand paper was the most effective for increase of germination. Singh et al. (1985) in lentil and Padma et al. (1994) in Leucaena, Alkbizzia and Samanea also observed similar result with sand paper. Contrary to the present results, Padma et al. (1994) reported increased percentage of germination with grind stone scarification and nicking.

Seed treatment with conc. sulphuric acid up to 30 minutes increased germination percentage to some extent (Table 1). This result corroborates the findings of Sinha et al. (1993), Padma et al. (1994) and Rao et al. (1985). However, the duration of soaking in sulphuric acid for better germination was different in different plant species.

The result of the present study revealed that hot water treatment of seeds for any duration and temperature did not improve germination percentage. These results are in agreement with the work of Jha and Sinha

\footnotetext{
* Corresponding author.
} 
(1989) in Vicia faba and Sinha et al. (1993) in Trigonella corniculata. However, Padma et al. (1994) reported hot water soaking $\left(80^{\circ} \mathrm{C}\right)$ for 5 minutes improved germination in Leucaena leucocephala, but not in Albizzia lebbeck and Samanea samon.

Presowing seed treatment with chemicals did not improve germination percentage. However, potassium nitrate and thiourea improved germination to some extent. (Table 1). Increased germination following treatment with potassium nitrate has been documented in Glycine max and Momordica charantia (Devi and Selvarj 1994). Increased germination following thiourea has been reported in marigold (Selvaraju 1986) and bitter gourd (Devi and Selvaraj 1994). Basra et al. (1990) reported that seed soaking treatment with potassium nitrate, $\mathrm{GA}_{3}$ and phthalimide increased seed germination in Panicum maximum. Devi and Selvaraj (1994) also observed enhanced germination of bitter gourd due to seed soaking with a number of chemicals like, bavistin, boric acid, calcium hydroxide, calcium oxychloride, sodium dihydrogen phosphate, potassium dihydrogen phosphate, succinic acid and NAA. But in the present study, some of these chemicals failed to elicit any positive effect on germination of $R$. serpentina seeds.

As mechanical and chemical scarification of seeds could not improve germination of $R$. serpentina seeds, it appears that germination inhibitors may be located inside the seeds. It appears that seed germination of $R$. serpentina is very complex and further work is necessary to understand the mechanism of germination.

Table 1. Effect of pre-sowing seed treatment on $\%$ of germination of R.serpentina.

\begin{tabular}{|c|c|c|c|c|}
\hline Treatment & & $\%$ germination & Treatment & $\%$ germination \\
\hline Control & & 26 & Heat treatment & \\
\hline \multirow[t]{4}{*}{ Scarification } & & & $70^{\circ} \mathrm{C} 16 \mathrm{~h}$ & 28 \\
\hline & Sand paper & 48 & $24 \mathrm{~h}$ & 28 \\
\hline & Grind stone & 32 & $48 \mathrm{~h}$ & 32 \\
\hline & Nicking & 30 & $72 \mathrm{~h}$ & 26 \\
\hline \multirow[t]{5}{*}{ Hot water } & & & $96 \mathrm{~h}$ & 28 \\
\hline & $5 \mathrm{~min}$ & 26 & $80^{\circ} \mathrm{C} 16 \mathrm{~h}$ & 28 \\
\hline & $10 \mathrm{~min}$ & 24 & $24 \mathrm{~h}$ & 30 \\
\hline & $15 \min$ & 28 & $48 \mathrm{~h}$ & 32 \\
\hline & $20 \mathrm{~min}$ & 28 & $72 \mathrm{~h}$ & 30 \\
\hline \multirow[t]{9}{*}{ Sulphuric acid } & & & $96 \mathrm{~h}$ & 28 \\
\hline & $3 \min$ & 25 & $90^{\circ} \mathrm{C} 16 \mathrm{~h}$ & 26 \\
\hline & $5 \mathrm{~min}$ & 25 & $24 \mathrm{~h}$ & 28 \\
\hline & $10 \mathrm{~min}$ & 26 & $48 \mathrm{~h}$ & 30 \\
\hline & $15 \mathrm{~min}$ & 30 & $72 \mathrm{~h}$ & 30 \\
\hline & $30 \mathrm{~min}$ & 38 & $96 \mathrm{~h}$ & 28 \\
\hline & $45 \mathrm{~min}$ & 32 & $1 \%$ Boric acid & 32 \\
\hline & $60 \mathrm{~min}$ & 30 & $1 \%$ Calcium hydroxide & 30 \\
\hline & $90 \mathrm{~min}$ & 25 & $1 \%$ Sodium dihydrogen phosphate & 30 \\
\hline \multirow[t]{9}{*}{ Hydrochloric acid } & & & $1 \%$ Potassium dihydrogen phosphate & 30 \\
\hline & $3 \min$ & 30 & $1 \%$ Potassium nitrate & 40 \\
\hline & $5 \mathrm{~min}$ & 28 & $0.5 \%$ Thiourea & 30 \\
\hline & $10 \mathrm{~min}$ & 32 & $100 \mathrm{ppm} \mathrm{GA}$ & 32 \\
\hline & $15 \mathrm{~min}$ & 26 & 100ppm NAA & 30 \\
\hline & $30 \mathrm{~min}$ & 32 & & \\
\hline & $45 \mathrm{~min}$ & 28 & & \\
\hline & $60 \mathrm{~min}$ & 27 & & \\
\hline & $90 \mathrm{~min}$ & 27 & & \\
\hline
\end{tabular}




\section{References}

Badhwar R L, Karira G V and Ramaswami S (1956) Methods of propagation and their effect on root production in Rauwolfia serpentina. Indian J. Pharm. 18: 170-175.

Basra A S, Grewal, R D Kapur A and Malik C P (1990) Overcoming germination barriers in guinea grass seeds. Indian J. Plant Physiol. 33: 371-373.

Devi J R and Selvaraj J A (1994) Effect of presowing treatment on germination and vigour in bitter gourd (Momordica charantica L.) cv. Co. 1. Seed Res. 22: 64-65.

Dutta P K, Choudhury S B and Rao P R (1962) Germination and chemical composition of Rauwolfia serpentina seeds. Indian J. Pharm. 24: 61-63.

Jha B N and Sinha R P (1989) Hardseededness in Vicia faba L. FABIS News Letter 24: 37.

Nayar S L (1956) Experimental propagation and culture of Rauwolfia serpentina Benth. by seeds. Indian J. Pharm. 18: 125-126.

Padma V, Satyanarayana G and Reddy B M (1994) Effect of scarification treatments on the germination of Leucaena leucocephala, Albizzia lebbeck and Samanea samon. Seed Res . 22: 54-57.

Rao N K, Vander Maesem L J G and Remanandan P (1985) Breaking seed dormancy in Atylosia species. Seed Res. 13: $47-50$.

Selvaraju P (1986) Studies on certain aspects of production, treating and storage of seed in marigold (Tagetes erecta L.). M Sc (Ag.) Thesis, Tamil Nadu Agri. University, India.

Singh J N, Jha B N, Sinha S K and Singh R S P (1985) Effect of seed treatment on dormancy of lentil seeds. Seed Res. 13: 28-32.

Sinha S K, Jha B N and Varshney S K (1993) Effect of various treatments on harseededness in kasurimethi (Trigonella corniculata L.). Seed Res. 21: 114-116. 